\title{
Experimental Evaluation of Turbine Ventilators Performance under Different Test Conditions
}

\author{
Dovydas Rimdžius , Juozas Bielskus, Vytautas Martinaitis, Violeta Motuzienė, and Giedrè Streckienė \\ Department of Building Energetics, Vilnius Gediminas Technical University, Vilnius, Lithuania
}

\begin{abstract}
One of the most popular wind driven ventilation devices is a turbine ventilator. Its main construction components usually are air suction duct and impeller. However, there are many different configurations of such devices - different shape of vanes and ratios between main dimensions. In order to develop turbine ventilators there is demand for deeper fundamental researches. Major part of previous experimental investigations compares turbine ventilators performance. The aim of presented experimental investigation is to understand key parameters affecting wind driven ventilators performance. For this purpose, straight and curved vane devices under 4 different test conditions are tested. All tests are performed in modified wind tunnel based on the following methodology: 1) testing devices under normal operation conditions; 2) testing without impeller; 3) testing while impeller is stopped; 4) testing while air suction duct is sealed. Experimental results have shown that the biggest part of extracted air flow rate is impacted due to ejection of wind and air suction duct interaction process. A slight increase in performance of turbine ventilators compared to open duct column has been confirmed. Experiments also revealed differences between tested turbine ventilators rotational speed trends. Presented empirical equations of experiments could be used for design of turbine ventilators or other researches purposes.
\end{abstract}

\section{Introduction}

Nowadays energy consumption of the modern buildings heating is highly reduced, meanwhile air flow required for ventilation persists the same or even gets higher. Therefore, electricity consumed by ventilation fans, constitutes a significant share in energy efficient buildings total energy demand. In order to maintain proper indoor air quality in buildings and ensure high efficiency of ventilation system, new solutions are required. Currently there are attempts being made to use technological solutions employing renewable energy. One of possible solutions is to use wind driven technologies. Recently wind driven rooftop turbine ventilators (RTV) is a spreading technology which has a simple construction and is relatively cheap.

Lai [1] has performed experiments in low-speed wind tunnel, seeking to define efficiency of RTV. He has confirmed that it is an effective technology to ventilate buildings and extracted air flow rate of the RTV depends on its size. However, influence of the size is not as significant, as expected.

The results of Bay et al. showed that when buoyancy effects were dominant, the open duct column performed better than roof turbine ventilator [2]. There were also tests of combined column-turboventilator prototype. Performance of the combined device was found to be better than that of standard RTV due to stack effects gained by an increased suction duct height.
Jadhav et al. observed that RTV with larger suction duct diameter gives more mass flow rate and less rotational speed compared to small size ventilator [3]. They also created CFD model and determined that CFD mass flow rate results are observed to be within $12 \%$ to $15 \%$ higher than the experimental results.

Rashid et al. studied aerodynamic forces on straight vane rotating wind driven ventilator and determined that tested ventilator was more efficient in operation at low wind speed than at high speed [4]. It is also concluded the increase of wind flow force on ventilator construction and flattening of lift force curves towards larger speed. Researchers concluded that partial flow separation might have been occurring on the blades at those speeds.

Investigation of Khan et al. concludes that turbine ventilator may not necessarily be the cheapest and most efficient option [5]. The standard vent hats showed similar abilities to the tested turbine ventilator comparable in size. However, researchers claim that turbine ventilator is more weather resistant and most importantly prevents wind-induced down draughts.

Lien et al. experimental and numerical analysis results indicate that the efficiency and reliability of a turbine ventilator operation may require boosting by hybrid system by incorporating other power sources such as solar power to overcome the inertia and friction forces acting on the body to initiate ventilator rotation at lower wind speed [6]. Lai additionally installed an inner fan powered with photovoltaic panels, at the bottom of RTV 
and found increase of ventilation air flow rate at wind speed up to $5 \mathrm{~m} / \mathrm{s}$ [7]. However, ventilation rate was not increased by installing an inner fan at higher wind flow velocities.

Review of recent researches indicates that most experiments of turbine ventilators are targeted at their performance investigation. However, many experiments are performed under different pressure conditions and it is difficult to make proper comparison of results. Other problem is lack of fundamental researches of phenomenon occurring on these devices. The interaction between characteristic processes of turbine, ventilator and ejector takes place there. Due to complex processes of air flows mixing inside turbine ventilator, it is difficult to understand different flow impact on its performance.

To solve problem related to comparison of results and in order to better understand key parameters of the turbine ventilator's performance, experimental evaluation of two different type RTV's is performed under different test conditions. Presented experimental results could be useful for comparison purposes and for turbine ventilator future development. The methods for better performance comparison between devices of different sizes and calculation of extracted air flow ratios are suggested.

\section{Test devices}

During experiment 2 different types of turbine ventilators are tested. One of them has straight vanes (on the left in Fig. 1) and another has curved vanes (on the right in Fig. 1). The first one is manufactured by Australian company "Edmonds" and its model is
"Hurricane 100". The second one is distributed by Polish company and its model is called "SXWO130MAXAL/CENTRO”.

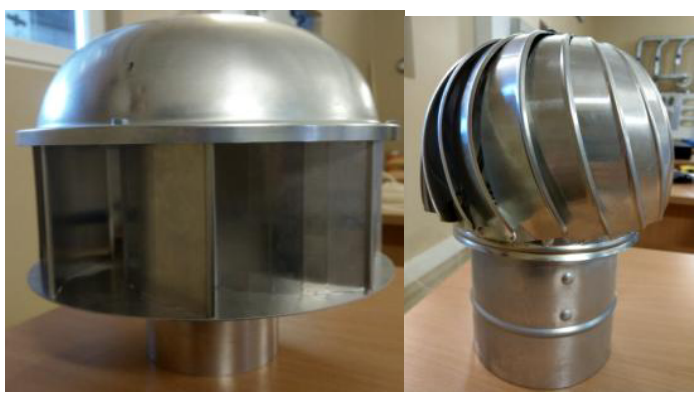

Fig. 1. Photos of tested turbine ventilators.

Because of different construction of vanes, tested devices are similar size but not identical. RTV with straight vanes has a bigger impeller while with curved vanes a bigger air suction duct hole. Main dimensions of the analysed RTV's are specified in Table 1.

Table 1. Dimensions of tested turbine ventilators.

\begin{tabular}{|c|c|c|}
\hline Dimensions & $\begin{array}{c}\text { Straight vane } \\
\text { turbine } \\
\text { ventilator }\end{array}$ & $\begin{array}{c}\text { Curved vane } \\
\text { turbine } \\
\text { ventilator }\end{array}$ \\
\hline $\begin{array}{c}\text { Air suction duct } \\
\text { diameter, mm }\end{array}$ & 110 & 130 \\
\hline $\begin{array}{c}\text { Impeller } \\
\text { diameter, mm }\end{array}$ & 280 & 190 \\
\hline $\begin{array}{c}\text { Impeller height, } \\
\text { mm }\end{array}$ & 92 & 130 \\
\hline
\end{tabular}

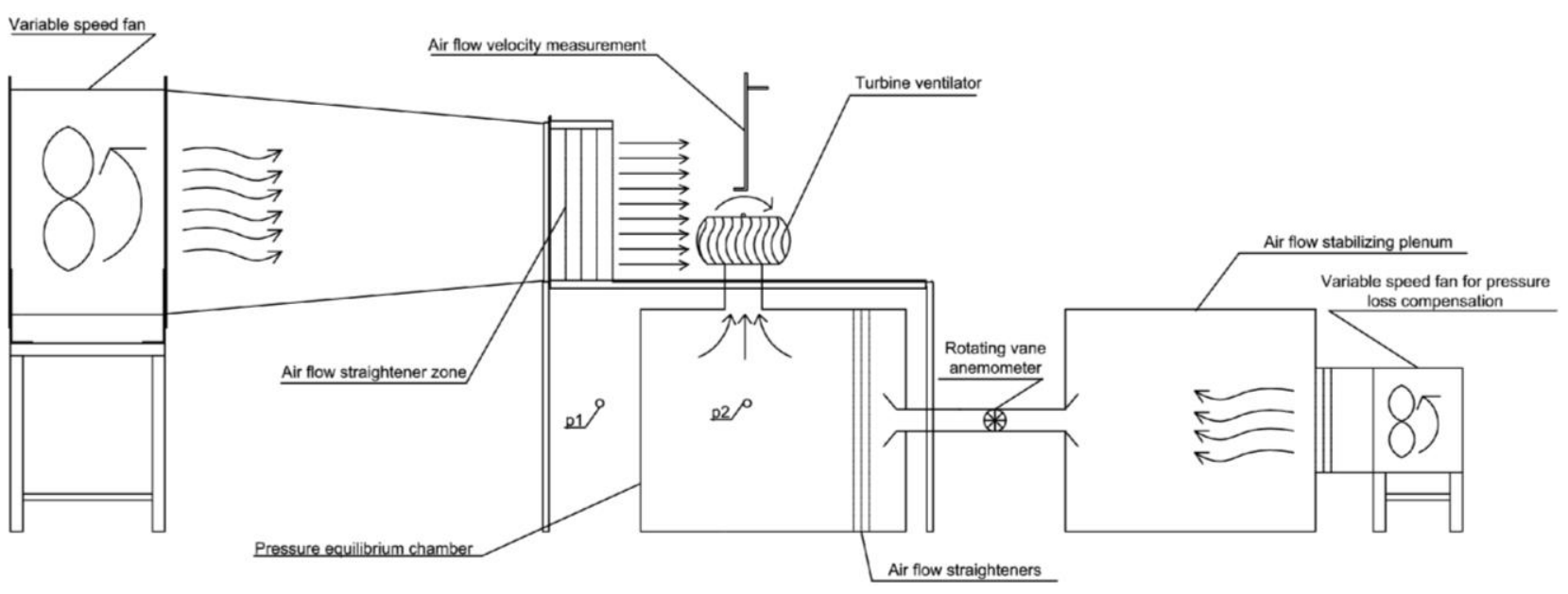

Fig. 2. Schematic of experimental setup and measurement points.

\section{Methodology}

\subsection{Experimental setup}

Experimental setup illustrated in Fig. 2 is based on AS/NZS 4740:2000 [8] standard and ideas of experiments published by other authors $[3,5,9]$. The construction base is made of modified open circuit wind tunnel with a variable speed fan. Tested RTV's are placed in the centre of direct wind flow and attached to the chamber of imitated ventilation room (in Fig. 2 it is called pressure equilibrium chamber). This chamber was well insulated with sealant and before experiments pressurized and tested with fumes. There wasn't almost any visual leakage while it was pressurized up to more than $300 \mathrm{~Pa}$. During experiments it is important to ensure 
uniform wind flow. For this purpose, air flow straightening zone with specific screens is integrated.

Experimental setup has pressure measurement point outside of experimental stand $\left(p_{1}\right)$ and 2 pressure measurement points on side walls of chamber $\left(p_{2}\right)$. For better accuracy last measurement points are attached by piezometric ring principle. For sucked air flow measurement 5 identical rotating vane anemometers "Ahlborn FVAD15S140" of $1.85 \mathrm{~cm}$ diameter, which are capable to measure up to $40 \mathrm{~m} / \mathrm{s}$ air velocity are used.

These rotating vane anemometers are connected between pressure equilibrium chamber and air flow stabilizing plenum. The latter plenum is attached to another variable speed fan and is used for pressure loss compensation.

Another important parameter of experiments is wind flow velocity. In this experimental setup it is measured by Pitot tube. Also, it is necessary to measure rotational speed of turbine ventilator. For this task used optical tachometer "Extech RPM33".

\subsection{Test conditions}

Prior the measurements being taken, a wind tunnel variable speed fan calibration was performed. The purpose of this was to determine wind flow velocity on specific test rig fan rotational speeds. For equal measuring conditions wind flow velocity is measured without turbine ventilator in apparent central position of it. Measurements were taken with pitot tube in 7 different positions and then averaged. It was determined that such test setup is capable to blow up to $9 \mathrm{~m} / \mathrm{s}$ wind flow.

In order to determine air flow components of tested devices, experiment was split in 4 different series. Further
Table 2 details every type of experimental series and shows which parameters were measured.

The first experimental series was performed without turbine ventilator. Instead equal diameter air suction duct which height is up to turbine ventilator impeller bottom was used. During second experiment ventilator is connected to chamber of imitated ventilation room and it is tested under normal operation conditions. Purpose of the next experiment is to determine turbine ventilator's extracted air flow rate while rotation of impeller is stopped. The aim of the last experiment configuration is to compare RTV's rotational speed performance while its air suction duct is closed.

During operation turbine ventilator creates negative pressure in room imitating chamber. However, such phenomenon in reality is highly dependent on room's tightness therefore it is difficult to compare devices performance results of other installations. To solve this problem all experiments are performed with pressure equilibrium conditions. It is done by equalizing static pressure in chamber and outside of experimental stand $\left(p_{1}=p_{2}\right)$. For this purpose, the second variable speed fan is used.

Since tested devices are not of equal size, for comparison purpose specific air flow calculation index is used. The equation of this calculation:

$$
Q_{s}=\frac{4 \cdot Q}{\pi \cdot d_{i}^{2}}
$$

Where $Q_{s}$ is a specific extracted air flow rate in $\mathrm{m}^{3} /\left(\mathrm{h} \mathrm{m}^{2}\right), Q$ is an absolute extracted air flow rate in $\mathrm{m}^{3} / \mathrm{h}$ and $d_{i}$ is an internal diameter of air suction duct.

Table 2. Configurations of experiment.

\begin{tabular}{|c|c|c|c|c|}
\hline \multirow{2}{*}{ Test conditions } & \multicolumn{3}{|c|}{ Experimental series } \\
\cline { 2 - 5 } & $\begin{array}{c}\text { Without } \\
\text { turbine } \\
\text { ventilator }\end{array}$ & $\begin{array}{c}\text { Turbine ventilator } \\
\text { operates normally }\end{array}$ & $\begin{array}{c}\text { Stopped rotation } \\
\text { of turbine } \\
\text { ventilator }\end{array}$ & $\begin{array}{c}\text { Closed air } \\
\text { suction duct }\end{array}$ \\
\hline Control of wind flow velocity & + & + & + & + \\
\hline Closed air suction duct & & & + & + \\
\hline Attached to pressure equilibrium chamber & + & + & + & \\
\hline Measured parameters & & + & & + \\
\hline Extracted air flow, m $^{\text {/h }}$ & + & + & + & + \\
\hline Rotational speed of turbine ventilator, RPM & + & + & + & + \\
\hline Wind speed velocity, m/s & + & + & + & + \\
\hline $\begin{array}{c}\text { Static pressure outside of experimental stand, } \\
\text { Pa }\end{array}$ & + & + & + & + \\
\hline $\begin{array}{c}\text { Static pressure in pressure equilibrium } \\
\text { chamber, Pa }\end{array}$ & + & + & + & + \\
\hline
\end{tabular}

Another calculation is performed to compare tested turbine ventilators extracted air flow rate ratios to wind flow rate:

$$
\eta=\frac{Q}{v_{w} \cdot A_{\text {imp }} \cdot 3600}
$$

Where $\eta$ is turbine ventilator extracted air flow rate ratio to wind flow rate perpendicular to impeller projection, $v_{w}$ is wind flow velocity in $\mathrm{m} / \mathrm{s}$ and $A_{\text {imp }}$ is area of impeller projection perpendicular to wind flow in $\mathrm{m}^{2}$.

\section{Experimental results}

In this chapter results of turbine ventilator air flow components and comparison of 2 tested devices performance are presented. Empirical equations attached to graphs are valid only for studied turbine ventilators. 
The first experimental results are presented in Fig. 3 and show extracted air flow rate against wind flow velocity under 3 different test conditions: without turbine ventilator (marked open duct), normal and stopped rotation.

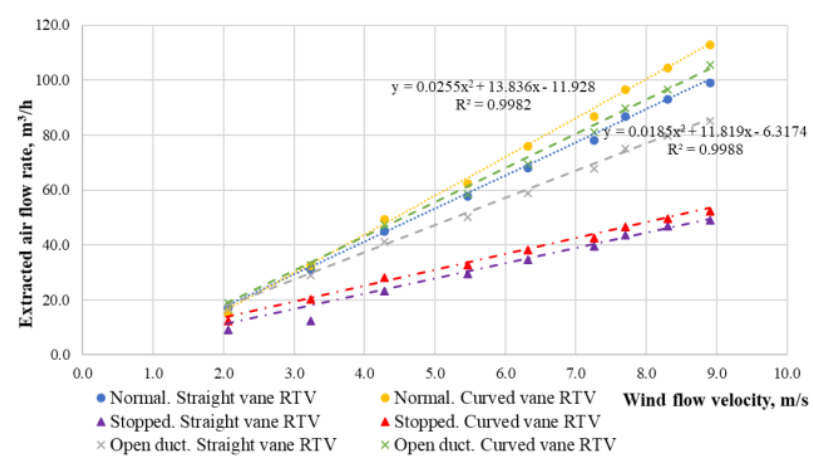

Fig. 3. Extracted air flow rate against wind flow velocity.

During experiments it was observed that rotation of turbine ventilators starts only when wind flow velocity is higher than $2 \mathrm{~m} / \mathrm{s}$. At lower velocity, used measurement devices weren't fairly accurate and because of that it was made an assumption that there isn't any air suction.

Analysis of the results shows that in both cases of tested devices the best extracted air flow performance is reached under normal test conditions. However, curved vane turbine ventilator extracts up to $12 \%$ more air flow compared to straight vane RTV at the same wind flow velocity.

It is evident that stopping of turbine ventilators does not completely block air suction because of ejection. Though such operation highly impacts their performance. In this case the impact of stopped ventilator test condition reduces nominal performance more than $50 \%$. It could be ventilation problem if rotation mechanism is damaged.

This graph illustrates minor difference between open duct and turbine ventilator performances. However, differently from other investigation results [5], turbine ventilators perform better than open duct. Looking more detail to extracted air flow curves it can be seen that rotation of straight vane RTV has more impact for sucked air flow than curved vane RTV. Turbine ventilators can extract up to $18 \%$ more air flow than open duct and curved vane ventilator only up to $7 \%$ on maximum tested wind flow velocity. Although curved vane ventilator impeller is higher, such difference could be mainly due to bigger straight vane ventilator impeller diameter and different aerodynamics.

From experimental data results it can be written these empirical equations for extracted air flow calculation:

$$
\begin{aligned}
& Q_{s t}=0.0185 \cdot v_{w}^{2}+11.819 \cdot v_{w}-6.3174 \\
& Q_{c u}=0.0255 \cdot v_{w}^{2}+13.836 \cdot v_{w}-11.928
\end{aligned}
$$

Where $Q_{s t}, Q_{c u}$ are extracted air flow rates in $\mathrm{m}^{3} / \mathrm{h}$ accordingly of straight vane and curved vane RTV's while static pressure is in equilibrium between room and atmosphere; $v_{w}$ is wind flow velocity in $\mathrm{m} / \mathrm{s}$.
Other experimental data results are plotted on rotational speed (RPM) against wind flow velocity graph in Fig. 4. This time there are presented only normal and closed air suction duct of turbine ventilators test conditions results.

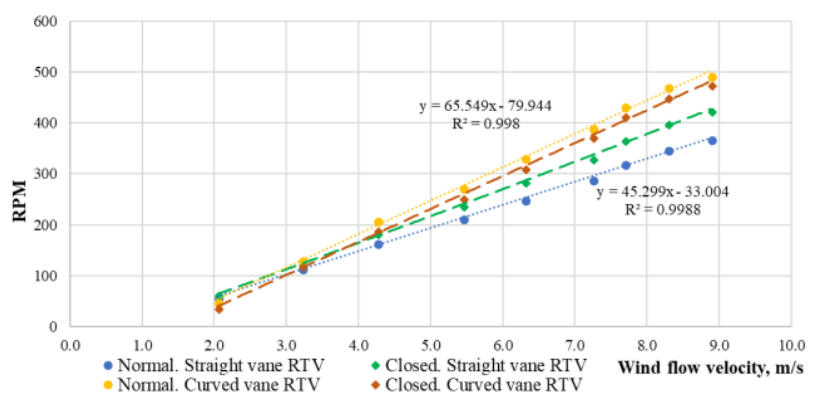

Fig. 4. Rotational speed against wind flow velocity.

Experimental results show that in both test series, curved vane ventilator reaches higher rotation speed. Under normal operation condition it is up to $34 \%$ higher compared to straight vane RTV's RPM.

However, as can be seen from all plotted curves the results are controversial. Analysing results of curved vane ventilator rotational speed, it is observed that under normal test conditions such device has a little bit higher (up to $4 \%$ ) RPM compared to case while its air suction duct is closed. On the other hand, rotational speed of straight vane ventilator has the opposite trend of change. While its air suction duct hole is sealed such device starts to rotate faster. During this test series, straight vane ventilator reached up to $15 \%$ higher RPM while its air suction duct was closed.

Supposedly such phenomenon could be explained by difference of such devices aerodynamics. During normal operation of curved vane ventilator its extracted air flow adds lift and drag forces to vanes and by this ensures faster rotation. However, construction of straight vane ventilator impeller creates different effect. This may be because during normal operation part of extracted air flow creates different direction aerodynamic drag forces and that stops rotation of impeller or creates air flow separation.

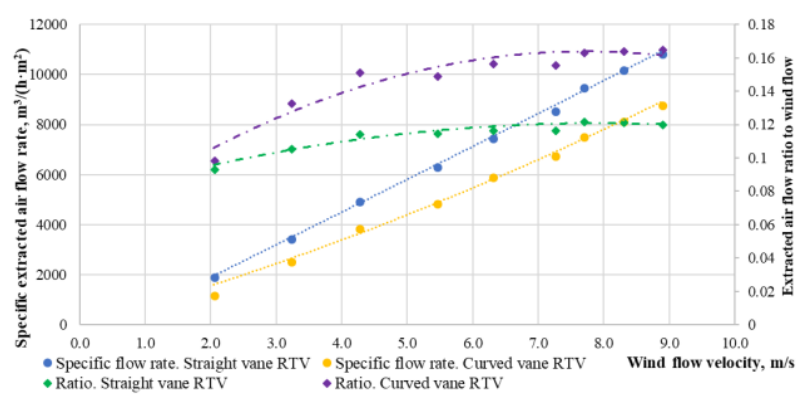

Fig. 5. Comparison of tested turbine ventilators performance.

Previous results (Fig. 3) showed better extracted air flow performance of curved vane ventilator. It should be kept in mind that these devices air suction duct sizes are not equal and as can be seen from figure 3 open ducts experimental results, sizes have significant impact. Inner 
diameters of air suction ducts are $108 \mathrm{~mm}$ and $128 \mathrm{~mm}$, but area differs more than $40 \%$. Therefore, comparison of their absolute air flow rate isn't objective and calculation of specific extracted air flow is used. The calculations are done by using (1) equation and the results plotted in Fig. 5 .

Results of specific extracted air flow rate calculations show opposite trend compared to absolute values. It can be seen that this time straight vane turbine ventilator has better performance (up to $23 \%$ ) but the change of trends remains similar.

Another important factor to RTV's performance is impeller size. Based on this factor, additionally there is calculated extracted air flow rate ratio to wind flow rate by (2) equation and the results plotted in the same Fig. 5. However, results of such calculations show better ratio of curved vane RTV. Analysis of curves indicates that performance of devices is similar on low wind flow velocity and difference gets higher up to $6 \mathrm{~m} / \mathrm{s}$. On higher wind speed difference between ratios remains almost the same.

\section{Conclusions}

Experiments of turbine ventilators under different test conditions revealed that the main effect for extracted air flow rate is due to ejection of wind and air suction duct interaction process. This is confirmed by test condition while ventilators are stopped and between differences during devices operate normally.

Controversial to some experimental investigations of such devices, it is determined ventilation flow rate increase while turbine ventilator is used, compared to open duct case. However, the performance increase is minor and reaches up to $18 \%$. Also, rotation of straight vane turbine ventilator has more impact on extracted air flow rate than curved vane ventilator. It could be mainly due to bigger straight vane ventilator impeller diameter and different aerodynamics. Different test conditions revealed that during periods when there isn't any rotation of turbine ventilator it makes huge impact to extracted air flow rate.
Comparing results of RTV's rotational speed under different test conditions, opposite trends are observed. During conditions while air suction duct is closed, straight vane turbine ventilator reaches higher RPM and curved vane turbine ventilator shows different trend. Supposedly such phenomenon could be explained by difference of such devices aerodynamics and flow separation.

Experimental results show that curved vane RTV reaches up to $12 \%$ higher absolute extracted air flow rate compared to straight vane RTV. Calculation of extracted air flow ratio to wind flow also indicates better results of curved vane RTV. However, recalculation to specific extracted air flow rate shows opposite results. Evaluation of impact due to different open duct area identifies better performance of straight vane RTV.

\section{Acknowledgement}

This research is funded by the European Regional Development Fund according to the supported activity 'Research Projects Implemented by World-class Researcher Groups' under Measure No. 01.2.2-LMT-K718 (project grant No 01.2.2-LMT-K-718-01-0016).

\section{References}

1. C. M. Lai, Energy Build., 35, 9, 927-932 (2003).

2. N. T. Bay and H. Phuong, Int.J. Eng. 6, 2, 86-95, (2012).

3. G. K. Jadhav, P. M. Ghanegaonkar, and S. Garg, J. Build. Eng., 6, 196-202 (2016).

4. D. M. H. Rashid and N. A. Ahmed, Wind Eng., 27, 1, 63-72 (2003).

5. N. Khan, Y. Y. Su, S. B. Riffat, and C. Biggs, Renew. Energy, 33, 11, 2441-2447 (2008).

6. J. Lien and N. A. Ahmed, Wind Driven Ventilation for Enhanced Indoor Air Quality, 2002.

7. C. M. Lai, Energy Build., 38, 3, 174-180 (2006).

8. AS/NZS 4740:2000, Australian/New Zealand Standard. Natural ventilators-Classification and performance, p. 46 (2000).

9. Y. Sik, D. Hun, H. Chung, H. Jeong, and S. Choi, Energy Build., 139, 232-241 (2017). 